\title{
Determination of activity of antioxidants in human subjects
}

\author{
Garry G. Duthie \\ Rowett Research Institute, Greenburn Road, Aberdeen AB21 9SB, UK
}

\begin{abstract}
Evidence from biochemical and animal models suggests that nutritional antioxidants should inhibit the development of diseases such as CHD and certain cancers. This evidence is not clearly corroborated by intervention studies in human subjects, due, in part, to inadequacies in current analytical methodologies. Although in vitro assays can give useful information on the attributes required by a compound to act as an antioxidant, results may have little nutritional relevance due to limited bioavailability. The determination of antioxidants in blood is often used as a measure of antioxidant status in vivo, but may not necessarily reflect concentrations in target tissues where oxidative stress is greatest. In addition, the accumulation of antioxidants in selective tissues may not be apparent from plasma measurements. Participation in quality-control schemes for antioxidant determination by HPLC allows inter-laboratory comparison of results. Moderation of indices of oxidative damage to lipids, proteins and DNA can provide information on the effectiveness of compounds as nutritional antioxidants. However, most current methods of assessing oxidative stress are subject to confounding factors of non-oxidative origin. Assays for total antioxidant capacity in plasma differ in their type of oxidation source, target and measurement used to detect the oxidized product. They give different results, should never be used in isolation, and results should be interpreted with caution. Until more is known about the activity and metabolic fate of antioxidants, caution should be exercised in the consumption of large amounts of commercially-available antioxidant preparations.
\end{abstract}

Antioxidants: Oxidative damage

Diseases are an unpleasant hazard of living. Although philosophers such as Rudolf Steiner indicated that the process of attempting to overcome disease can assist the individual in his or her spiritual quest (Wilkinson, 1993), more simply most of us would like to avoid illness and fulfil our allotted time unencumbered with serious clinical syndromes. As there is now such a large body of evidence implicating oxidative reactions in the pathogenesis of many diseases (for example, see Jackson, 1999), the popular media and the health supplement industries at times appear to suggest that the holy grail of maintaining optimum health throughout life can be achieved by the simple expedient of consuming antioxidants. Thus, there is now a huge range of antioxidant-containing concoctions and capsules available from commercial outlets. Cynics may say that the primary aim of antioxidants is to make profits for the producer rather than benefit the consumer. However, there is very strong biochemical and animal model evidence suggesting that certain antioxidants should prevent or inhibit disease progression. As yet this evidence has not been clearly corroborated by epidemiological and intervention studies with human subjects. In addition, there are also disconcerting reports from some clinical trials of adverse effects of antioxidant supplements. Some of the uncertainty about the benefits of antioxidants to human health may be due, in part, to the inadequacy of experimental approaches and to the misinterpretation of results generated by current methodologies. Consequently, the aim of the present review is to give a brief account of how antioxidants function and to then describe the advantages and disadvantages of various methods of assessing antioxidant activity in clinical, nutritional and epidemiological settings.

\section{Antioxidant mechanisms and definitions}

In brief, antioxidants can prevent or inhibit oxidation by:

(1) decreasing localized $\mathrm{O}_{2}$ concentrations so that oxidation is less likely to occur;

(2) preventing initiation reactions by scavenging free radicals which are capable of directly abstracting $\mathrm{H}$ from molecules;

Abbreviations: $\mathrm{ABTS}^{\bullet+}$, 2,2'-azinobis-3-ethylbenzothiazoline-6-sulfonic acid radical; BHT, butylhydroxytoluene; DEA, 1,4-dioxan-ethanol-acetonitrile (20:20:40, by vol.); MPA, metaphosphoric acid.

Corresponding author: Dr G. G. Duthie, fax +44 (0)1224 716622, email ggd@ rri.sari.ac.uk 
(3) binding transition metal ion catalysts such as $\mathrm{Cu}$ and $\mathrm{Fe}$ to prevent generation of initiating free radicals;

(4) decomposing peroxides to prevent their conversion to further active and initiating radical species;

(5) reacting with chain-propagating radicals such as the peroxyl and alkoxyl radicals to prevent continued $\mathrm{H}$ abstraction from fatty acid side chains.

Some of these mechanisms are exploited by the food industry, which uses a range of synthetic and natural antioxidants to retard oxidative rancidity of foods. Thus, the US Department of Agriculture's Code of Federal Regulations (Food and Agriculture Organization/World Health Organization, 1987) defines antioxidants as 'substances used to preserve food by retarding deterioration, rancidity, or discoloration due to oxidation'. However, as it is now appreciated that living organisms are exposed to a range of oxidizing species which have the potential to damage biomolecules such as proteins, lipids and DNA, a more appropriate definition of antioxidants for the present article is "compounds that protect biological systems against the potentially harmful effects of processes or reactions that can cause excessive oxidations' (Krinsky, 1992). Such compounds can be of endogenous or exogenous origin, and contribute to the complex and integrated biological antioxidant defence system which normally protects cells from the injurious effects of oxidation. This process is achieved by directly scavenging reactive oxygen and nitrogen free radical species, by metabolizing lipid peroxides to nonradical products and by chelating metal ions to prevent the generation of oxidizing species (Halliwell, 1990).

\section{Antioxidant nutrients}

In general, biological antioxidants are characterized by being readily absorbed, transported to the relevant site within the cell for optimum function and are non-toxic at nutritionally-relevant intakes. The main ones we require from the diet will be discussed:

\section{D- $\alpha$-Tocopherol (Vitamin E)}

One of eight naturally-occurring vitamin E compounds that are synthesized by plants from homogentistic acid, $D$ - $\alpha$-tocopherol is a derivative of 6-chromanol with a saturated $\mathrm{C}_{16}$ phytol side chain. It is an example of a phenolic antioxidant. Such molecules readily donate the $\mathrm{H}$ from the $\mathrm{OH}$ group on the ring structure to free radicals which then become unreactive (Fig. 1). On donating the $\mathrm{H}$ the phenolic itself becomes a relatively unreactive free radical, because the unpaired electron on the $\mathrm{O}$ can be delocalized into the aromatic ring structure thereby increasing its stability (Scott, 1997). Its major biological role is to protect polyunsaturated fats and other components of cell membranes from oxidation by free radicals and is, therefore, primarily located within the phospholipid bilayer of cell membranes. It is particularly effective in preventing lipid peroxidation, a series of chemical reactions involving the oxidative deterioration of polyunsaturated fatty acids (see Duthie, 1993). Vegetable oils are major sources of $\mathrm{D}-\alpha$-tocopherol in food products, although other plant-based

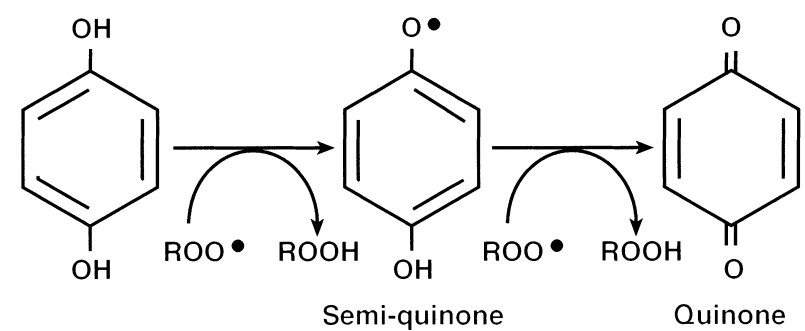

Fig. 1. Simple two-step hydrogen donation by a phenolic antioxidant to lipid radicals (ROO*). The resulting unpaired electron becomes delocalized within the ring structure so that the phenolic radical is relatively unreactive before ultimately forming a quinone.

food groups also provide significant sources of the vitamin. For a detailed review of biochemical and nutritional aspects of vitamin E, see Duthie (1999).

\section{Vitamin C}

Vitamin C (L-ascorbic acid) can be synthesized from D-glucose or D-galactose in the liver of most higher organisms except primates (including Homo sapiens), guinea-pigs, an Indian fruit-eating bat and some species of birds (for review, see Halsted, 1993). The latter depend on dietary sources for adequate supply. Major sources include a wide range of vegetables and fruit. Vitamin $\mathrm{C}$ is one of the most important water-soluble antioxidants in cells, efficiently scavenging a range of reactive oxygen species such as $\mathrm{O}^{-}{ }_{2}, \mathrm{OH}^{*}$, peroxyl radicals and singlet oxygen (Sies et al. 1992). By efficiently trapping peroxyl radicals in the aqueous phase of the plasma or cytosol, vitamin $\mathrm{C}$ can protect biomembranes and LDL from peroxidative damage. In addition to acting as an oxygen scavenger it can also chelate trace elements such as $\mathrm{Fe}$ and $\mathrm{Cu}$ which catalyse the decomposition of hydroperoxides to initiate free radical chains. Moreover, vitamin $\mathrm{C}$, at least in chemical systems, donates a $\mathrm{H}$ to the tocopheroxyl radical. However, whether such effective regeneration of vitamin $\mathrm{E}$ by vitamin $\mathrm{C}$ occurs in vivo has yet to be convincingly demonstrated (Halliwell, 1996).

\section{Carotenoids}

Carotenoids are synthesized by photosynthetic microorganisms and plants but not by animals. Particularly rich sources are yellow-orange fruits and dark green leafy vegetables. About 700 naturally-occurring carotenoids have been identified to date, of which about fifty can serve as precursors for vitamin A (Olsen, 1992). All carotenoids are primarily symmetrical $\mathrm{C}_{40}$ polyisoprenoid structures with an extensive conjugated double-bond system. In general, major dietary classes of carotenoids are hydrocarbon carotenoids (carotenes), O-containing carotenoids (xanthophylls) and carotenyl fatty acid esters (Beecher \& Khachik, 1992). Whether the primary roles of carotenoids are as biological antioxidants is a matter of debate. However, there is little doubt that because of their polyene structural feature, a number show strong reactions with reactive oxygen species in chemical and biochemical systems. For example, $\beta$-carotene has long been known to be a particularly 
effective scavenger of singlet oxygen (Bendich \& Olsen, 1989). This ability is also shared by $\alpha$-carotene, lycopene, zeaxanthin, lutein and $\beta$-cryptoxanthin, and appears to depend largely on physical quenching as opposed to chemical reaction. Antioxidant efficacy of certain carotenoids is also apparent in non-photochemical free radicalmediated reactions. For example, $\beta$-carotene has also been shown to inhibit peroxidation of liposomal phospholipids exposed to a range of free radical generators, including azo-dye-induced peroxyl radicals, superoxide and transition metals (Liebler et al. 1997). In these systems antioxidant effects are seen over a range of $\mathrm{O}_{2}$ tensions within the normal physiological range. Nutritional aspects of carotenoids have been reviewed recently by Castenmiller \& West (1998).

\section{Trace elements}

A number of enzymes with antioxidant function require trace elements from the diet as cofactors. Cytoplasmic and mitochondrial superoxide dismutases $(E C$ 1.15.1.1) require $\mathrm{Cu}, \mathrm{Zn}$ and $\mathrm{Mn}$ to catalyse the removal of superoxide radicals. $\mathrm{H}_{2} \mathrm{O}_{2}$ in the cell is removed by catalase (EC 1.16.1.6) which requires $\mathrm{Fe}$, and also by Se-containing GSH peroxidases (EC 1.11.1.9) which can also metabolize lipid hydroperoxides.

\section{Other contenders}

In general the previously mentioned compounds are recognized as being essential because: (1) a deficiency causes a defined disease to develop, e.g. severe vitamin $\mathrm{C}$ deficiency causes scurvy, and combined vitamin E and Se deficiencies cause myopathies and neuropathies (Combs, 1992). Moreover, such conditions can be reversed by repletion with the appropriate micronutrients; (2) they are readily absorbed and are likely to be near the biomolecules in the cell where oxidative damage is most likely to occur; (3) in fulfilling their role as antioxidants, they do not cause marked damage to cellular processes in vivo; (4) in nutritionally-relevant amounts, they moderate markers of oxidative stress and/or disease risk.

Many compounds which as yet have not fulfilled the previously mentioned criteria have been proposed to act as antioxidants in vivo. Some of these compounds will be discussed.

\section{Ubiquinone}

Ubiquinone is a lipophilic quinone which is similar in structure to vitamin $\mathrm{E}$ and which functions as an electron carrier in the mitochondrial electron transport chain of the cell. However, it also protects membrane phospholipids and those in LDL from peroxidation (Cabrini et al. 1986), and therefore has antioxidant properties. Ubiquinone is synthesized in the body from precursors of cholesterol synthesis. For this reason it is not classed as a vitamin. However, the ability to synthesize ubiquinone decreases with age, and it has been proposed that there may be an increasing dependence on food to supply the nutrient. Major sources are meats, vegetable oils and grain germs (Beyer et al. 1986).

\section{a-Lipoic acid}

Thioctic acid ( $\alpha$-lipoic acid) plays an essential role in mitochondrial dehydrogenase reactions, and the reduced form, dihydrolipoate, reacts with reactive oxygen species such as $\mathrm{O}_{2}^{-}$, $\mathrm{OH}^{*}$, peroxyl radicals and singlet oxygen. It may also protect cell membranes as it interacts with vitamin $\mathrm{C}$ and GSH. Major food sources include liver and yeast (Packer et al. 1995).

\section{Melatonin}

This chief secretory product of the pineal gland scavenges free radicals such $\mathrm{OH}^{*}$ by electron donation, and has the potential to protect nuclear DNA, membrane lipids and cytosolic proteins from oxidative damage. It has been used mainly in human volunteers in pharmacological doses, and whether significant antioxidant effects are detectable at the lower nutritionally-relevant quantities is unclear (for review, see Reiter et al. 1997).

\section{Plant polyphenols}

There is currently enormous interest in the antioxidant potential of polyphenolic products of the phenylpropanoid biosynthetic pathway in plants (for review, see Duthie $e t$ al. 1999). These products include compounds such as ellagic acids, chalcones and flavonoids including the anthocyanins, coumarins, hydroxycinnamic and hydroxybenzoic acids, and catechin derivatives). In a manner similar to vitamin $\mathrm{E}$, they have the potential to act chemically as antioxidants by ready donation of electrons or $\mathrm{H}$ from their hydroxyl moieties. Many of these compounds have marked antioxidant abilities in vitro, but their role as nutritional antioxidants is not proven. Moreover, many natural phenolics function in plants to discourage attack by fungal parasites, herbivorous grazers and pathogens. Their consumption to excess by mammals could cause adverse metabolic reactions.

\section{Measuring antioxidant activity in vitro}

There are many methods in the literature for assessing the antioxidant activity of compounds in vitro. Most methods assess the ability of compounds to donate a $\mathrm{H}$ or electron to an oxidizing species introduced into the assay system. Such approaches can give useful information on the attributes required by a compound to function as an antioxidant. For example, using standard stoppedflow electron spin resonance spectrometry methodology, the decay of the radical resonance of the semi-stable galvinoxyl radical (2,6-di-tert-butyl- $\alpha$-(3,5-di-tert-butyl-4oxo-2,5-cyclohexadien-1-ylidene)-p-tolyloxy) can be followed in organic media with respect to time. The kinetics and stoichiometry of the process of $\mathrm{H}$ transfer between the compound and the synthetic radical can be used as a measure of antioxidant activity. Application of the technique to natural polyphenols such as flavonoids indicate that 
reactivity is highly dependent on the configuration of $\mathrm{OH}$ groups on the $\mathrm{B}^{-}$and $\mathrm{C}$-ring systems, and that many can undergo multiple $\mathrm{H}$ or electron transfer steps (Gardner et al. 1997; McPhail et al. 1999).

Although such information is useful in ascertaining the antioxidant potential of a compound, results can differ depending on the assay system used. A typical example of the variation between assays concerns the phyto-oestrogens, which have phenolic hydroxyl groups on the A and/or B rings and thus could act as antioxidants in cells. Mitchell et al. (1998) found that using an assay based on the ability of compounds to reduce the 2,2'-azinobis-3-ethylbenzothiazoline-6-sulfonic acid radical $\left(\mathrm{ABTS}^{\circ+}\right)$, the antioxidant activity of many phyto-oestrogens is similar or greater than that of vitamin $\mathrm{C}$. However, the same compounds show only minimal antioxidant capacity in systems based on the reduction of a ferric-tripyridyltriazine complex or the galvinoxyl radical. This disparity probably reflects the strength of the oxidizing species used in the assay, the greater aggression of the $\mathrm{ABTS}^{-+}$species compared with the other oxidants inducing reaction with additional A-ring hydroxyls. As most compounds will act as antioxidants if the oxidizing species is strong enough, results from such in vitro assays should be treated with caution, and certainly not be used to ascribe antioxidant function in biological systems.

\section{Measuring antioxidant activity in vivo}

Many compounds with in vitro antioxidant activity may have little in vivo relevance because they are not bioavailable. These chemicals may not be extracted from the food matrix in the gut and may be susceptible to destruction by gut flora. In addition, absorption through the intestinal wall may not take place, or they may be rapidly metabolized by the liver and excreted via the bile. For example, the fruits and vegetables normally consumed in the human diet contain more than forty different types of carotenoids, but only fourteen of these have as yet been identified in tissue and plasma (Beecher \& Khachik, 1992). Similarly, although the process of absorption of all eight tocopherol homologues in our diet is similar, the $\alpha$-form predominates in blood and tissue, despite some of the other forms being more potent antioxidants in chemical systems. This situation is due to the action of binding proteins which preferentially select the $\alpha$-form. In the first instance, a $30 \mathrm{kDa}$ binding protein unique to the liver cytoplasm preferentially incorporates $\alpha$-tocopherol into the nascent VLDL (Traber \& Kayden, 1993). Intracellular transport is also expedited by a $14.2 \mathrm{kDa}$ binding protein which binds $\alpha$-tocopherol in preference to the other homologues (Dutta-Roy et al. 1994). These selective mechanisms explain why vitamin $\mathrm{E}$ homologues have markedly differing antioxidant abilities in biological systems, and illustrates the important distinction between the in vitro antioxidant effectiveness of a substance in the stabilization of, for example, a food product and its in vivo potency as an antioxidant. Thus, the most important approach to assess whether an antioxidant has a role in a biological context is to detect its presence and assess its effects in the organism.

\section{Detection of antioxidants in vivo}

HPLC is widely used to measure some antioxidant nutrients in blood. For example, many methods exist to detect vitamin $\mathrm{E}$ and carotenoids in plasma (Fig. 2); such methods usually involve the addition of an organic solvent to aid protein precipitation of the sample and separation of the tocopherols and carotenoids into the organic layer (Rumley \& Paterson, 1998). Vitamin E and carotenoids are stable at $-80^{\circ}$ for many months, particularly if a synthetic antioxidant such as butylhydroxytoluene is added to the plasma before freezing. Samples should be protected from light to avoid destruction of the carotenoids; use of brown vials in the autosampler is recommended. As extraction methods, anticoagulants, storage conditions and operator competence can influence the accuracy of measurement (Rumley \& Paterson, 1998), participation in a quality-assurance scheme is worthwhile, particularly for nutritional or epidemiological studies involving analytical laboratories in different locations. An example of a 'round-robin' scheme for lipid-soluble antioxidants is the National Institute of Standards/National Cancer Institute Micronutrient Measurement Quality Assurance Program (US Department of Commerce, National Institute of Standards and Technology, Gaithersburg, MD 20899-0001, USA). The method currently used in our laboratory for the detection of tocopherols and carotenoids in human plasma is given in Appendix 1.

There are several simple HPLC methods for determination of vitamin $\mathrm{C}$ in plasma. Most methods require sample acidification using metaphosphoric acid or perchloric acid immediately after harvesting to avoid artifactual oxidation. Simultaneous measurement of dehydroascorbate and ascorbate may be a useful indicator of oxidative stress. However, most methods involve the initial determination of ascorbic acid, then dehydroascobate is reduced to ascorbate and the measurement repeated, allowing calculation of the dehydroascorbate by difference. Thus, it is not always clear whether dehydroascorbate is normally present in plasma or has arisen due to inadequacies

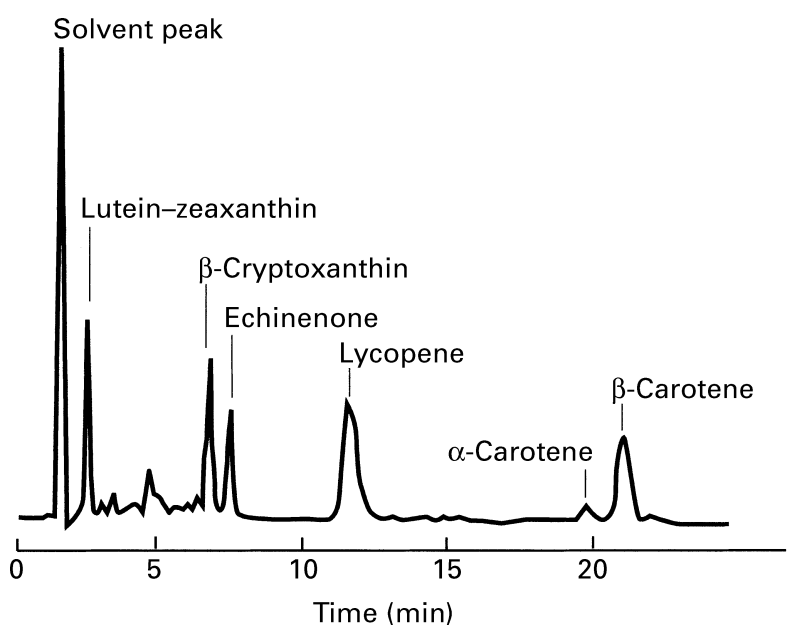

Fig. 2. Chromatogram showing the major carotenoids identified in plasma. Echinenone was used as an internal standard. For further details, see Appendix 1. 
in sample handling and storage. Moreover, as the stability of ascorbate can also be affected by temperature and $\mathrm{pH}$, as with the lipid-soluble antioxidants, participation in a quality assurance programme, for example that run by the National Institute of Standards/National Cancer Institute, should be considered. The method for the determination of vitamin $\mathrm{C}$ in plasma used by our laboratory is given in Appendix 2 .

Recently, methods have been developed to measure some polyphenols such as flavonoids and their conjugates in plasma and urine. Early animal studies (Das, 1969) indicated that the absorption of flavonoids was inhibited because of their destruction by intestinal micro-organisms. However, a variety of methods (for example, see Hollman et al. 1997; Paganga \& Rice-Evans, 1997) are under development which suggest that some polyphenols and their glycosides appear in plasma following consumption of flavonoid-rich meals. As yet such methods are not widely used and are analytically demanding. No inter-laboratory quality assurance scheme currently exists to assess the advantages and disadvantages of these methods.

Whereas many epidemiological and clinical studies use plasma antioxidant concentrations as a measure of anti- oxidant status, such values require cautious interpretation as they may not necessarily reflect concentrations in target tissues where oxidative stress is greatest. For example, plasma vitamin E concentrations vary little over a wide range of dietary intakes, whereas concentrations in tissues such as liver, heart and adipose tissue can respond much more markedly. In addition, certain carotenoids can accumulate in specific tissues (Sies et al. 1992), and therefore their concentration may not reflect those in plasma. Moreover, transient increases in plasma antioxidant concentrations following consumption of antioxidant-rich foods and beverages may also give misleading information about the habitual antioxidant status of an individual.

\section{Indices of oxidative damage}

Another means of estimating the activity of antioxidants in vivo is to assess their effects on markers of oxidative damage to lipids, proteins and DNA. One problem with this approach is that many such indices are non-specific and assays can be subject to interference from compounds of non-peroxidative origin (Table 1). In addition, such indices

Table 1. Some methods for the detection of oxidative damage to lipids, protein and DNA in human subjects

\begin{tabular}{ll}
\hline $\begin{array}{l}\text { Peroxidative product } \\
\begin{array}{l}\text { Thiobarbituric acid-reactive } \\
\text { substances }\end{array}\end{array}$ & $\begin{array}{l}\text { Malonaldehyde, a product of lipid } \\
\text { peroxidation, is coupled to thiobarbituric } \\
\text { acid and the resulting chromogen is usually } \\
\text { measured by its fluorescence }\end{array}$ \\
Conjugated dienes & $\begin{array}{l}\text { Early product of lipid peroxidation cascade. } \\
\text { Detected at about 230-235 nm }\end{array}$
\end{tabular}

Hydrocarbons $\quad \begin{aligned} & \text { End-products of lipid peroxidation, e.g. } \\ & \text { ethane and pentane arise from } \\ & \text { peroxidation of } n-3 \text { and } n-6 \text { fatty acids } \\ & \text { respectively } \\ & \text { Several methods available, e.g. chemi- } \\ & \text { luminescence, iodometry and ferrous } \\ & \text { oxidation in xylol orange }\end{aligned}$
Comments

Widely used and technically simple. Works well in animal models. However, subject to confounding by compounds of nonperoxidative origin in plasma or urine of human subjects. Specificity improved by HPLC. Also affected by Fe content of buffers and reagents. Marked variation in values for healthy subjects between different laboratories

Subject to confounding by dienes of dietary origin. Some purines, proteins and haem absorb at similar wavelengths leading to interference. Detection of individual dienes by HPLC may increase specificity but no benchmark values for normal subjects

Non-invasive means of estimating overall lipid peroxidation in vivo. However, susceptible to interference from hydrocarbons leaching from fat stores, pollution and intestinal organisms. Not practical for studies involving large numbers of subjects

Specificity may be improved by HPLC and separation of plasma or urine into a polar solvent. However, some methods subject to confounding by proteins and haemoglobin. Commercially-available kits not adequately validated at present

$\mathrm{F}_{2}$-isoprostanes $\quad$ Product of free radical-mediated oxidation of Possibly very specific and has potential to be a 'gold-standard' for phospholipids containing arachidonic acid assessing lipid peroxidation ex vivo in plasma and urine. However, currently technically complex requiring access to mass spectrometer (MS). Commercially-available ELISA kit not adequately validated as yet

Protein carbonyls Possible products of free radical damage to Widely used but no standardized procedure and markedly different amino acids measured after reaction with values between laboratories for healthy subjects. May be subject to 2,4-dinitrophenylhydrazine confounding from endogenous and exogenous carbonyls of non-protein derivation

8-Hydroxy-deoxyguanosine Tentative product of repair of oxidative damage to DNA in cells such as lymphocytes which is possibly excreted into urine. Detected by HPLC with electrochemical detection or by GC-MS

May serve as a marker of integrated rate of DNA damage in whole body. Technically complex and up to 10 -fold lower baseline values obtained by HPLC compared with MS. Possible confounding effects from artifactual formation during sample preparation (GC-MS) or incomplete enzymic hydrolysis (HPLC). Commercial ELISA kits not yet validated

Comet assay Harvested lymphocytes lysed and subjected Sensitive semi-quantitative measure which may reflect oxidative to electrophoresis, and free DNA arising burden to DNA in whole organism. Labour intensive and subject to from strand breaks and oxidized bases assessment variation. Sensitivity increased by application of visualized using fluorescence microscopy enzymes which recognize oxidized bases, although may be underestimation if all such bases not accessible to enzyme 
may only be markedly elevated in individuals with overt clinical conditions or nutrient deficiencies, and may not respond in healthy individuals to intervention with antioxidants. However, some lifestyle activities such as smoking and excessive exercise do increase indices of oxidative stress in vivo, and therefore individuals undertaking such activities can be suitable models to assess antioxidant effectiveness of compounds. For example, plasma of smokers has a twofold higher concentration of $\mathrm{F}_{2}$-isoprostanes than that of non-smokers (Morrow et al. 1995), which is indicative of the enhanced peroxidation of arachidonic acid. In addition, less-specific indices of lipid peroxidation such as thiobarbituric acid-reactive substances, conjugated dienes, fluorescent products and lipid peroxides are increased in plasma of smokers, indicating that the inhalation of tobacco smoke induces a sustained oxidant stress which overwhelms the capacity of the antioxidant defence system (Duthie, 1999b).

Several studies have therefore assessed whether supplementation of smokers with antioxidants ameliorates enhanced indices of oxidative stress. For example, increased pentane expiration by smokers, which indicates enhanced peroxidation of $n-6$ polyunsaturated fatty acids, can be reduced by supplementation with $800 \mathrm{mg}$ vitamin E/d for 2 weeks (Hoshina et al. 1990). In addition, the elevated plasma concentrations of lipid peroxides, thiobarbituric acid-reactive substances and conjugated dienes in smokers compared with non-smokers were significantly decreased $(P<0.001)$ in the smokers following consumption of $280 \mathrm{mg}$ DL- $\alpha$-tocopheryl acetate/d for 10 weeks (Brown et al. 1994, 1997). As yet few if any studies have assessed whether intakes or plasma and tissue levels of compounds such as flavonoids, catechins, coumarins and anthocyanins are less in smokers compared with non-smokers, and whether increasing intakes modify indices of oxidative stress.

\section{Assays for total antioxidant capacity}

In contrast to specific assays for the determination of antioxidants, various methods have been devised to measure the overall antioxidant activity of plasma or serum. As with methods to assess activity in chemical systems, all methods measure the inhibition of an artificially-generated oxidative process by antioxidants in the plasma or serum. Methods differ in the choice of oxidation source, target and the type of measurement used to detect the oxidized product (see Woodford \& Whitehead, 1998). Although such methods can show changes in plasma antioxidant activity following consumption of antioxidant-rich foods and beverages (for example, see Fig. 3), results require cautious interpretation. Some methods record albumin as an antioxidant, which can confound the measurement of the antioxidant capacity of the recognized antioxidants in plasma. Others methods give predominance to the antioxidant activity of urate and bilirubin, so that dietary manipulation with vitamin $\mathrm{E}$, vitamin $\mathrm{C}$ and carotenoids may not result in detectable changes in plasma antioxidant capacity despite an increase in plasma concentrations of these compounds. Moreover, some methods do not respond to $\mathrm{SH}$ group-containing antioxidants (Woodford \& Whitehead, 1998). Invariably, the
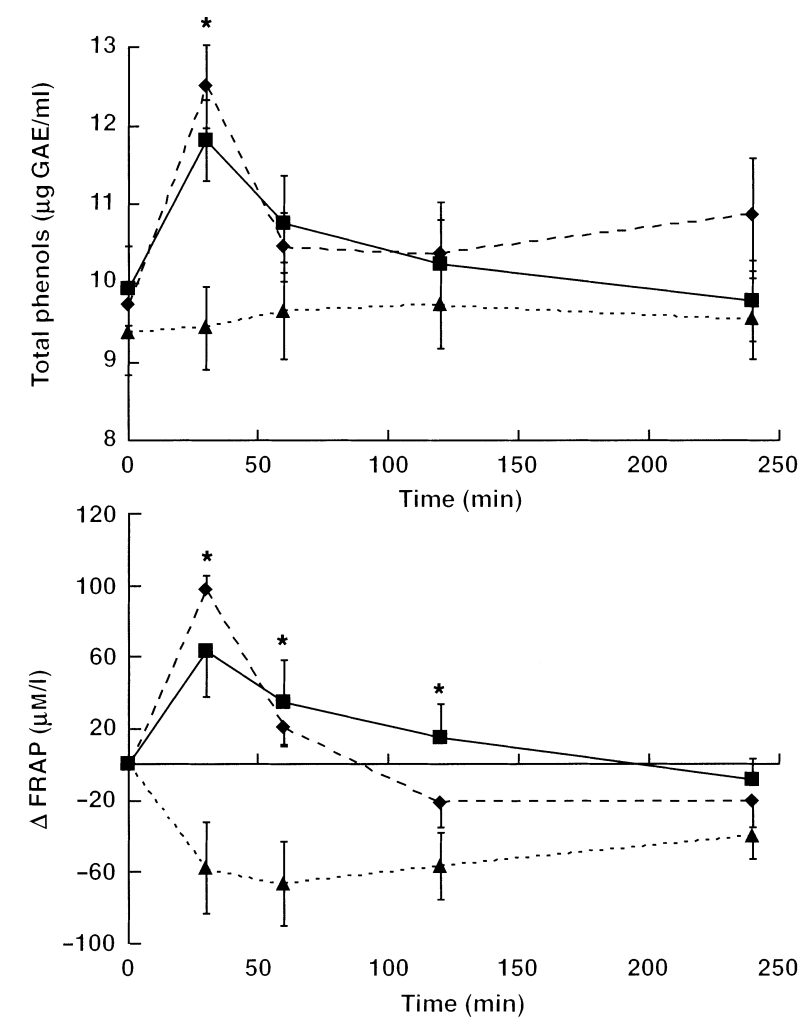

Fig. 3. The effect of drinking $100 \mathrm{ml}$ wine $(\bullet)$, whisky ( $\mathbf{\square})$ or newmake spirit (phenolic-free control spirit obtained before maturation of the whisky in the cask; $\mathbf{\Delta}$ ) on the total phenolic concentration and total antioxidant potential of plasma from male volunteers, as determined by the changes in ferric-reducing antioxidant potential $(\triangle \mathrm{FRAP})$. Values are means with their standard errors for nine subjects. There were significant increases $30 \mathrm{~min}$ after consumption of wine and whisky but not for newmake spirit: ${ }^{*} P<0.05$. (Adapted from Duthie et al. 1998.) GAE, gallic acid equivalents.

results of these assays give different results. For example, Cao \& Prior (1998) found little correlation between three assays for the determination of total antioxidant capacity of human serum. In addition, any observed changes in plasma antioxidant capacity after dietary manipulation does not necessarily imply that similar changes occur within relevant cells and tissues. Consequently, such assays should never be used in isolation, and results should be treated with caution.

\section{Antioxidants and heart disease: a cautionary tale}

Considerable in vitro evidence implicates the oxidation of LDL in the development of coronary artery disease (Steinberg, 1997). Oxidized LDL has a number of properties that could increase its atherogenicity. It is recognized by at least three types of scavenger receptors in macrophages which rapidly internalize the oxidized LDL. The macrophages are then transformed into 'foam-like cells' which in vivo could be are regarded as precursors to the development of the occlusive plaque. Moreover, several different animal models do suggest that increasing dietary intakes of some antioxidants can reduce the severity of vascular disease progression. For example, the feeding of antioxidants such as vitamin $\mathrm{E}$, probucol, butylhydroxytoluene and BO-653 
increases the resistance of LDL to oxidation, and reduces the lesions in arteries of rabbits, mice and monkeys which are either genetically-susceptible to vascular disease or have been fed atherosclerotic-promoting diets (Westhuyzen, 1997).

Such strong evidence for the therapeutic benefit of antioxidants has naturally lead to antioxidant supplementation trials with human subjects. However, the results from the few randomized double-blind placebo-controlled trials to date have been contradictory. For example, the Cambridge Heart Antioxidant Study (Stephens et al. 1996) involving 2000 men and women with angiographically-defined coronary artery disease resulted in a marked reduction in non-fatal myocardial infarction in subjects taking vitamin $\mathrm{E}$ compared with the placebo group, whereas the AlphaTocopherol and Beta-Carotene Study (Rapola et al. 1997) with 29000 male smokers found no effect of vitamin $E$ on coronary artery events. Although the latter study was primarily aimed at investigating the effects of antioxidant supplements on the incidence of lung cancer, a subpopulation of 1862 male smokers with a history of myocardial infarction were allocated daily in a double-blind design to $50 \mathrm{mg}$ vitamin $\mathrm{E}$ or $20 \mathrm{mg} \beta$-carotene, or both micronutrients, or a placebo. After a 5-year follow-up there were no statistically significant differences among the four groups in the total number of major coronary events. However, potential adverse effects were apparent as fatal heart disease was significantly lower $(P<0.007)$ in the placebo group and significantly higher (by $43 \% ; P<0 \cdot 007$ ) in those who took the carotenoid. In addition, in the overall study there were $18 \%$ more lung cancers and $8 \%$ greater mortality amongst those taking $\beta$-carotene compared with those on the placebo. Similarly the Beta-Carotene and Retinol Efficacy Trial (Omenn et al. 1996) involving 18000 smokers, former smokers and those individuals who had been exposed to asbestos indicated that supplementation with $30 \mathrm{mg} \beta$-carotene and $7500 \mu \mathrm{g}$ vitamin A increased the incidence of cardiovascular disease by $26 \%$ compared with the placebo group. This trial was terminated 21 months prematurely as after 4 years there were also $28 \%$ more lung cancers and $17 \%$ more deaths in the supplemented subjects compared with the placebo group.

Differences in outcomes between such intervention studies may reflect the range of doses used, the duration of supplementation and the health status of the volunteers at the start of the study. For example, many antioxidants can also act as pro-oxidants under a range of circumstances, and it is possible that unforeseen metabolic disturbances may occur after prolonged use of highly bioavailable pure compounds; such effects may not be apparent when antioxidants are obtained from foods.

\section{Conclusion}

In conclusion, there is considerable in vitro and animal model evidence that certain compounds with antioxidant activity may benefit health and prevent the development of some major diseases. However, the role of antioxidants in the prevention or cure of disease in human subjects is less convincing, as methodologies to assess the effects of antioxidant activity in human subjects are inadequate. In addition, trials with supplements have elucidated potential adverse effects. Although antioxidant supplements may be appropriate therapeutically in certain circumstances and for particular risk groups, increasing consumption of antioxidant-rich foods such as fresh fruits and vegetables is possibly a more appropriate strategy to increase antioxidant intake. Until we know more about the activity and metabolic fate of antioxidants in the body, it would be wise to be very cautious about the consumption of supra-physiological amounts of such bioactive compounds.

\section{Acknowledgements}

The author is grateful for support from the Scottish Office Agriculture Environment and Fisheries Department, the Ministry of Agriculture Fisheries and Food, the World Cancer Research Fund and the European Community FAIR Program.

\section{References}

Bendich A \& Olsen J (1989) Biological action of carotenoids. FASEB Journal 3, 1927-1932.

Beecher GR \& Khachik F (1992) Qualitative relationship of dietary and plasma carotenoids in human beings. Annals of the New York Academy of Sciences 669, 320-321.

Beyer RE, Nordenbrand K \& Ernster L (1987) The function of coenzyme Q in free radical production and as an antioxidant: A review. Chemica Scripta 27, 10-18.

Brown KM, Morrice PC \& Duthie GG (1994) Vitamin E supplementation suppresses indices of lipid peroxidation and platelet counts in blood of smokers and non-smokers but plasma lipoprotein concentrations remain unchanged. American Journal of Clinical Nutrition 60, 383-387.

Brown KM, Morrice PC \& Duthie GG (1997) Erythrocyte vitamin $\mathrm{E}$ and plasma ascorbate concentrations in relation to erythrocyte peroxidation in smokers and non-smokers: dose response of vitamin E supplementation. American Journal of Clinical Nutrition 65, 496-502.

Cabrini L, Pasquali P, Tadolini B, Sechi AM \& Landi L (1986) Antioxidant behaviour of ubiquinone and $\beta$-carotene incorporated into model membranes. Free Radical Research Communications 2, 85-92.

Cao G \& Prior RL (1998) Comparison of different analytical methods for assessing total antioxidant capacity of human serum. Clinical Chemistry 44, 1309-1315.

Castenmiller JJM \& West CE (1998) Bioavailability and bioconversion of carotenoids. Annual Review of Nutrition 18, $19-38$.

Combs GF (1992) The Vitamins. Fundamental Aspects in Nutrition and Health. London: Academic Press Inc.

Das NP (1969) Studies on flavonoid metabolism. Degradation of (+)-catechin by rat intestinal contents. Biochimica et Biophysica Acta 177, 668-670.

Duthie GG (1993) Lipid peroxidation. European Journal of Clinical Nutrition 47, 759-764.

Duthie GG (1999a) Vitamin E and its antioxidant role in relation to other dietary components. In Human Nutrition and Dietetics, 10th ed. [JS Garrow and WPT James, editors]. London: Churchill Livingstone Press (In the Press).

Duthie GG (1999b) Natural antioxidants in the protection against cigarette smoke injury. In Antioxidant Food Supplements in Human Health, pp. 35-42 [M Hiramatsu and L Packer, editors]. London: Academic Press. 
Duthie GG, Kyle J \& Duthie SJ (2000) Plant polyphenols: implications as nutritional antioxidants. Nutrition Research Reviews (In the Press).

Duthie GG, Pedersen MW, Gardner PT, Morrice PC, Jenkinson A McE, McPhail DB \& Steele GM (1998) The effect of whisky and wine consumption on total phenol content and antioxidant capacity of plasma from healthy volunteers. European Journal of Clinical Nutrition 52, 733-736.

Dutta-Roy AK, Gordon MJ, Campbell FM, Duthie GG \& James WPT (1994) Vitamin E requirements, transport, and metabolism: Role of $\alpha$-tocopherol-binding proteins. Journal of Nutritional Biochemistry 5, 562-570.

Food and Agriculture Organization/World Health Organization (1987) Report of FAO/WHO Expert Committee on Food Additives. Technical Report Series no. 751-758. Geneva: WHO.

Gardner PT, McPhail DB \& Duthie GG (1997) Electron spin resonance spectroscopic assessment of the antioxidant potential of teas in aqueous and organic media. Journal of the Science of Food and Agriculture 76, 257-262.

Halliwell B (1990) How to characterise a biological antioxidant. Free Radical Research Communications 9, 1-32.

Halliwell B (1996) Vitamin C: Antioxidant or pro-oxidant in vivo. Free Radical Research 25, 439-454.

Halstead CN (1993) Water-soluble vitamins. In Human Nutrition and Dietetics 9th ed., pp. 239-264 [JS Garrow and WPT James, editors]. London: Churchill Livingstone Press.

Hollman PCH, van Trijp JMP, Buysman MNCP, Gaag MS, Mengelers JB, de Vries JHM \& Katan MB (1997) Relative bioavailability of the antioxidant flavonoid quercetin from various foods in man. FEBS Letters 418, 152-156.

Hoshina ER, Shariff A, Van Gossum A, Allard JP, Pichard C, Kurian R \& Jeejebhoy KN (1990) Vitamin E suppresses increased lipid peroxidation in cigarette smokers. Journal of Parenteral and Enteral Nutrition 14, 300-305.

Jackson MJ (1999) An overview of methods for assessment of free radical activity in biology. Proceedings of the Nutrition Society 58, 1001-1006.

Krinsky NI (1992) Mechanism of action of biological antioxidants. Proceedings of the Society for Experimental Biology and Medicine 200, 248-254.

Liebler DC, Stratton SP \& Kaysen KL (1997) Antioxidant actions of beta-carotene in liposomal and microsomal membranes: Role of carotenoid-membrane incorporation and alpha-tocopherol. Archives of Biochemistry and Biophysics 338, 244-250.

McPhail DB, Gardner PT \& Duthie GG (1999) Kinetic and stoichiometric assessment of the antioxidant activity of flavonoids by ESR spectroscopy. Free Radical Biology and Medicine (In the Press).

Mitchell JH, Gardner PT, McPhail DB, Morrice PC, Collins AR \& Duthie GG (1998) Antioxidant efficacy of phytoestrogens in chemical and biological model systems. Archives of Biochemistry and Biophysics 360, 142-148.
Morrow JD, Frei B, Longmire W, Goziano M, Lynch SM, Shyr Y, Strauss W, Oates JA \& Roberts LJ (1995) Increase in circulating products of lipid peroxidation (F2-isoprostanes) in smokers. Smoking as a cause of oxidative damage. New England Journal of Medicine 64, 1198-1203.

Olsen JA (1992) Carotenoids and vitamin A: An overview. In Lipid Soluble Antioxidants, pp. 178-192 [ASH Ong and L Packer, editors.] Basel: Birkhauser.

Omenn GS, Goodman GE \& Thornquist MD (1996) Effects of a combination of beta-carotene and vitamin A on lung cancer and cardiovascular disease. New England Journal of Medicine 334, $1150-1155$.

Packer L, Witt EH \& Tritchler HJ (1995) Alpha-lipoic acid as a biological antioxidant. Free Radical Biology and Medicine 19, 227-250

Paganga G \& Rice-Evans CA (1997) The identification of flavonoids as glycosides in human plasma. FEBS Letters 401, $78-82$.

Rapola J, Virtamo J \& Ripatti S (1997) Randomised trial of alphatocopherol and beta-carotene supplements on incidence of major coronary events in men with previous myocardial infarction. Lancet 349, 1715-1720.

Reiter R, Tang L, Garci JJ \& Muñoz-Hoyos A (1997) Pharmacological actions of melatonin in oxygen radical pathophysiology. Life Sciences 60, 2255-2271.

Rumley AG \& Paterson JR (1998) Analytical aspects of antioxidants and free radical activity in clinical biochemistry. Annals of Clinical Biochemistry 35, 181-200.

Scott G (1997) Antioxidants in Science, Technology, Medicine and Nutrition. Chichester, West Sussex: Albion Publishing.

Sies H, Stahl W \& Sundquist AR (1992) Antioxidant functions of vitamins: Vitamin $\mathrm{E}$ and $\mathrm{C}$, beta-carotene and other carotenoids. Annals of the New York Academy of Sciences 669, 7-20.

Stephens NG, Parsons A \& Schofield PM (1996) Randomised control trial of vitamin $\mathrm{E}$ in patients with coronary disease: Cambridge Heart Antioxidant Study (CHAOS). Lancet 347, 781-786.

Steinberg D (1997) Low density lipoproteins and its pathological significance. Journal of Biological Chemistry 272, 2096320966.

Traber MG \& Kayden HJ (1993) $\alpha$-Tocopherol as compared with $\gamma$-tocopherol is preferentially secreted in human lipoproteins. Annals of the New York Academy of Sciences 570, 95-108.

Westhuyzen J (1997) The oxidation hypothesis of atherosclerosis: an update. Annals of Clinical Laboratory Science 27, 1-10.

Wilkinson R (1993) Rudolf Steiner; Anthroposophy, vol. 1. London: Temple Lodge Publishing.

Woodford FP \& Whitehead TP (1998) Is measuring serum antioxidant capacity clinically useful? Annals of Clinical Biochemistry 35, 48-56. 


\section{Appendix 1}

HPLC determination of carotenoids, tocopherols and retinol in plasma

Principle of assay. The assay comprised a reversed-phase HPLC method which allowed the simultaneous measurement of retinol, six carotenoids, and $\gamma$-tocopherol and $\alpha$-tocopherol in plasma using fluorescence and visible detection, based on Hess et al. (1991).

Solutions required. These were:

(1) methanol containing $10 \mathrm{~g}$ butylhydroxytoluene (BHT)/1;

(2) hexane containing $500 \mathrm{mg}$ BHT/1;

(3) 1,4-dioxan-ethanol-acetonitrile (20:20:40, by vol.; DEA)

(4) ammonium acetate (10 g/l water).

Preparation of mobile phase. The mobile phase comprised: acetonitrile-tetrahydrofuran-methanol containing BHT-ammonium acetate $\quad(10 \mathrm{~g} / \mathrm{l}$; 67.4:22:6 8:3.8, by vol.).

Sample preparation. Fresh whole blood was centrifuged at $1500 \mathrm{~g}$ at $4^{\circ}$. Approximately $500 \mu \mathrm{l}$ plasma was pipetted into a microtube and snap-frozen in liquid $\mathrm{N}_{2}$ before storing at $-70^{\circ}$.

Sample extraction. Plasma $(200 \mu \mathrm{l}), 200 \mu \mathrm{l}$ water and $400 \mu \mathrm{l}$ ethanol were pipetted into a $2 \mathrm{ml}$ microtube, mixed in a whirlimix (Water, Watford, Herts., UK) for $10 \mathrm{~s}$ and $700 \mu \mathrm{l}$ hexane (containing BHT) and $100 \mu \mathrm{l}$ echinone. The microtube was shaken for $10 \mathrm{~min}$ on the vortex genie, then centrifuged for $5 \mathrm{~min}$. Of the hexane layer, $600 \mu \mathrm{l}$ was removed and was taken to dryness on the speed vac for 9 min. The dry sample was dissolved in $200 \mu \mathrm{l} \mathrm{DEA}$, and shaken for 5-10 min before application onto the HPLC column.

Chromatography. A Beckman Ultrasphere ODS $5 \mu \mathrm{m}$, $250 \mathrm{~mm} \times 4.6 \mathrm{~mm}$ i.d. column (Beckman, High Wycombe, Bucks., UK) in a column oven set at $29^{\circ}$ was used. Flowrate was $1.05 \mathrm{ml} / \mathrm{min}$ and the injection volume was $150 \mu \mathrm{l}$. The run time was $30 \mathrm{~min}$. Wavelengths were changed during the run as follows: visible detection: $0-11.9 \mathrm{~min}$ at $450 \mathrm{~nm}$, $12-17.4 \mathrm{~min}$ at $472 \mathrm{~nm}$, $17 \cdot 5-30 \mathrm{~min}$ at $450 \mathrm{~nm}$;

fluorescence detection: $0-5 \cdot 1 \mathrm{~min}, 330$ and 470 (excitation/and emission), 5.2-14.6 min, 298 and 328 , 14.7-30.0 min, 349 and 480 .

Equipment. An example of a suitable system is as follows: Waters 470 Scanning Fluorescence Detector, 486 Tuneable Absorbance Detector 600E System Controller, 712 WISP (Water, Watford, Herts., UK); Jones Chromatography Column Chiller Model 7955 (Jenes Hengued, Mid Glamorgan, UK). The system can be run using Millenium v 2.1 Software (Waters).

Quality control. Mixed standards (pre-prepared and stored at $-70^{\circ}$ ) containing carotenoids, retinol and tocopherol at appropriate concentrations must be included in the run. Every sixth sample was a standard pooled plasma and each run must contain echinone blanks (used as an internal standard as it does not co-elute with the other peaks. It can be obtained from Hoffman La Roche). Participation in a quality assurance scheme such as the fat-soluble vitamins 'round-robin' of the micronutrients measurement quality-assurance programme run from the US Department of Commerce, National Institute of Standards and Technology (Gaithersburg, MD 20899-0001, USA) should be considered. Fat-soluble vitamins in human serum SRM 986a, which can be obtained from National Institute of Standards and Technology, are used as international standards, and these standards were run every $14 \mathrm{~d}$.

\section{Reference}

Hess D, Keller HE, Oberlin B, Bonfanti R \& Schuep W (1991) International Journal of Vitamin and Nutrition Research 61, 232-238. 


\section{Appendix 2}

\section{HPLC determination of ascorbic acid and uric acid}

Principle of assay. The assay comprised simultaneous determination of the plasma concentration of ascorbic acid and uric acid by reversed-phase HPLC using an ion-pairing reagent with u.v. detection (Ross, 1994).

Solutions required. Ascorbic acid, EDTA, acetic acid, $\mathrm{NaOH}$ (all Analar grade), metaphosphoric acid (MPA; general purpose reagent grade), acetonitrile (HPLC grade) were purchased from Merck (Poole, Dorset, UK). Uric acid, homocysteine and myristyltrimethylammonium bromide were obtained from Sigma (Poole, Dorset, UK). MPA (50 and $100 \mathrm{~g} / \mathrm{l}$ ) was filtered and stored at $4^{\circ}$. The solution was stable for 3 weeks only. The myristyltrimethylammonium bromide solution contained $67 \cdot 28 \mathrm{~g} / \mathrm{l}$ water.

Preparation of mobile phase. The mobile phase comprised $4 \mathrm{~g} \mathrm{NaOH}+1400 \mathrm{ml}$ water, adjusted to $\mathrm{pH} 5 \cdot 0$ with acetic acid. EDTA (400 g) and $200 \mathrm{mg}$ homocysteine were added. Acetonitrile $(200 \mathrm{ml})$ was then added, the $\mathrm{pH}$ adjusted to $5 \cdot 5$, and the volume made up to $1750 \mathrm{ml}$ with water. The solution was filtered and made up to 2 litres with filtered myristyltrimethylammonium bromide.

Standards. The standards used were: $0.042 \mathrm{~g}$ uric acid dissolved in $50 \mathrm{ml}$ water (add a pellet of $\mathrm{NaOH}$ to dissolve); $0.0176 \mathrm{~g}$ ascorbic acid dissolved in $50 \mathrm{ml} \mathrm{MPA}(50 \mathrm{ml} / \mathrm{l})$. Both standards were diluted in MPA $(1: 10 ; \mathrm{v} / \mathrm{v}$ to give a final concentration of $200 \mu \mathrm{M}$ for ascorbic acid and $500 \mu \mathrm{M}$ uric acid. Standard curves of 0, 50, 100, 150 and $200 \mu \mathrm{M}$ (ascorbic acid) and 0, 125, 250, 375 and $500 \mu \mathrm{M}$ (uric acid) are prepared using MPA as diluent.

European and US Standards. European and US standards must be included in each run and can be purchased from Promochem Ltd (Welwyn Garden City, Herts., UK). The standards were prepared in concentrations of 25, 50, 75 and $100 \mu \mathrm{M}$ and are stored at $-70^{\circ}$. The standards (one of each concentration) were defrosted at $4^{\circ}$ (in a refrigerator) and pipetted into $2 \mathrm{ml}$ amber vials for application onto the HPLC.

Sample preparation. Plasma was obtained by centrifuging (1500 $g$ for $10 \mathrm{~min}$ ) heparinized whole blood at $4^{\circ}$. (Plasma should be harvested as soon as possible after the blood sample has been obtained to avoid destruction of vitamin C.) The freshly-taken blood was placed on ice until required for centrifugation. Plasma $(600 \mu \mathrm{l})$ and $600 \mu \mathrm{l}$ MPA (100 g/l) were pipetted into a microtube, mixed, snapfrozen and stored at $-70^{\circ}$ until required for HPLC analysis.

Sample preparation for HPLC analysis. Samples were defrosted at $4^{\circ}$ (in a refrigerator) and centrifuged at $10000 \mathrm{rev} . / \mathrm{min}$ for $10 \mathrm{~min}$ at $4^{\circ}$. The clear supernatant fraction was transferred into $2 \mathrm{ml}$ amber vial for application onto HPLC. Any cloudy samples were discarded.

Chromatography. The column was a Jones Chromatography (Jones, Henygoed, Mid Glamorgan, UK) Nucleosil ODS $5 \mu \mathrm{m}, 250 \mathrm{~mm} \times 4.6 \mathrm{~mm}$ i.d. with Supelco guard cartridge $\mathrm{C}_{18}$ and (Supelco, Poole, Dorset, UK) with reversed-phase packing $30-40 \mu \mathrm{m}$ (Perisorb RP 18; Anachem, Luton, Beds., UK). The flow-rate was $0.6 \mathrm{ml} / \mathrm{min}$ and run time was $12 \mathrm{~min}$. Detection was at $263 \mathrm{~nm}$.

Equipment. A suitable HPLC system consists of two pumps (e.g. Gilson 305; Gilson, Luton, Beds., UK) and a $20 \mu \mathrm{l}$ loop volume automated sampler module (e.g. Gilson 231) connected to a u.v. detector (e.g. Gilson 116). The automatic sampler must be kept at $4^{\circ}$ with suitable recirculating cooler (e.g. Techne FC-200; Gilson). Peak recording and detection can be done with a pen recorder, but many systems now use software such as Gilson 715 or Unipoint (Gilson).

Quality control. Plasma pools should be included at every ten to fifteen analyses and international standards at every twenty-five to thirty analyses. The method gives an inter-batch $\mathrm{CV}$ of less than $5 \%$ for both uric acid and ascorbic acid. Participation in 'round robin' assessment, such as that of the US Department of Commerce, National Institute of Standards and Technology, Gaithersberg, MD 20899-0001, USA should be considered.

\section{Reference}

Ross MA (1994) Determination of ascorbic acid and uric acid in plasma by high-performance liquid chromatography. Journal of Chromatography 657B, 197-200. 